\title{
Changes in Back Body Surface Measurements for Dynamic Postures in the Form of Baseball Batting Motion with a 3D body Scanning
}

The purpose of this study was to analyze human upper body surface changes at the shoulder and back area. The body surface data were analyzed in terms of muscle and bone displacement in dynamic postures. Body surface data were collected with a $3 D$ body scanner. The body surface was scanned at the static and four baseball batting postures. The body surface dimensions over the deltoids, scapulae and trapezius were measured. The results show that the vertical measurements of the deltoids increased by 20\%. The horizontal measurements of the axilla of the back increased. The surface of the trapezius was elongated by over 10\%, and the lower back musculature was elongated by about 50\%. The results of this study showed that changes in back body surface caused by upper arm movements. It was influenced by the deltoid articulated with the humeri and the scapulae and trapezius. These body surface changes caused by muscle activities and ranges of motion can be used to design functional clothing.

\section{INTRODUCTION}

High-performance clothing, such as sportswear or protective garments, should contribute to a coordination between body segments without

Ph.D. Candidate, Department of Clothing and Textiles, College of Human Ecology, Yonsei University (smshin1209@naver.com )

${ }^{\star}$ Professor, Department of Clothing and Textiles, College of Human Ecology, Yonsei University (jschun@yonsei.ac.kr)

Key Words: Body surface, upper arm, dynamic posture, 3D body scanning disturbances as the wearers move. Studies of ergonomic functional clothing have investigated sportswear and protective wear as well as patient wear (Çivitci, 2004) and smartwear (Toney et al., 2003). Facilitating unconstrained movement is of the primary aim of ergonomic functional clothing design. When designing ergonomic functional clothing, it is crucial to measure the physical dimensions of various postures so as to optimize the utility of the clothing to meet the kinetic demands of the human body.

Our body dimensions and shapes change as we move. The dimensions measured during dynamic postures provide information about adjustments that can be made to clothing in order to facilitate ease of motion. Thus, it is important to observe body surface changes for a variety of dynamic postures in order to design functional clothing that enhances kinetic functionality (Chun \& Oh, 2004).

The body surface, or human skin, extends or contracts in response to articular angle variations. Until recently, numerous studies attempted to explain body surface changes during dynamic motion. Chun \& Oh (2004) argued that body surface changes did not occur uniformly in all areas of the body during motion. Arm postures significantly affect shifts in body measurements related to the upper torso, such as the bust circumference and the posterior chest breadth (Lu et al., 2010). Measurements taken around the scapula, shoulder, upper arm, and side areas beneath the axilla change significantly 
Table 1. Measuring Methods for Body Surface Dimensional Changes in Previous Studies

\begin{tabular}{|c|c|c|c|}
\hline Methods & Researchers & Body parts & Experimental postures \\
\hline \multirow{2}{*}{$\begin{array}{l}\text { Manual tape } \\
\text { measurements }\end{array}$} & Chi \& Kennon (2006) & Upper body and arms & $\begin{array}{l}\text { Static standing, raising arms upward, stretching arms inward }\left(60^{\circ}\right) \text {, } \\
\text { stretching arms forward, stretching arms sideways }\left(180^{\circ}, 210^{\circ}\right)\end{array}$ \\
\hline & Wang et al. (2011) & Whole Body & Static standing, 17 dynamic postures \\
\hline \multirow{3}{*}{$\begin{array}{l}\text { Gypsum- } \\
\text { replicated }\end{array}$} & Kim \& Kim (1992) & Upper body and arms & Static standing, raising arms $\left(45^{\circ}, 90^{\circ}, 135^{\circ}, 180^{\circ}\right)$ \\
\hline & Kim et al. (1999) & Upper arms and scapulae & Static standing, raising arms $\left(45^{\circ}, 90^{\circ}, 135^{\circ}\right)$ \\
\hline & $\operatorname{Kim} \& \operatorname{Kim}(2003)$ & Whole Body & Static standing, cycling \\
\hline \multirow{4}{*}{$\begin{array}{l}\text { 3D body } \\
\text { scanning }\end{array}$} & Jung (2005) & Lower body & Static standing, cycling \\
\hline & Oh \& Chun (2008) & Upper body & Static standing, golf swing \\
\hline & Lu et al. (2010) & Torso & Two arm postures with palms facing backward or inward \\
\hline & Choi \& Ashdown (2010) & Lower body & $\begin{array}{l}\text { Standing with arms folded, } 120^{\circ} \text { knee-bend, one-pace, sitting with } \\
\text { a } 90^{\circ} \text { knee-bend }\end{array}$ \\
\hline
\end{tabular}

when the arms are up (Kim \& Kim, 1992), especially around the posterior axillae (Kim et al., 1999). Chi \& Kennon (2006) found that no area of the upper body changed more than $13 \mathrm{~cm}$ during dynamic motion.

For several years, studies of changes in measurements of the body in static and dynamic states have used anthropometric experiments. In general, objective methods have been used to define the proper amount of wearing ease by analyzing surface expansion and contraction during body movements (Wang et al., 2011). Many tools and techniques have been developed for anthropometry including manual tape measurements, and gypsum-replicated methods such as molding, and 3D body scanning (Table 1).

A 3D body scanner is an optical measurement tool that provides digital images of the surface geometry of the body. It offers images and measurement data about figures, calculated from the $\mathrm{x}, \mathrm{y}, \mathrm{z}$-coordinate dataset of the scanned objects (Ashdown et al., 2007). Speediness and reproducibility are the most important benefits of this method, although the risks include potentially missing data due to shading or errors because of movement artifacts (Daanen and M.Sc, 1998). Landmarks for 3D body scanning are generally identified by palpations of the body surface, including bony protrusions. Kouch \& Mochimaru (2011) stressed the importance of landmarking determined by an anthropometrist through palpation because it most seriously affects the scanning. Studies on the accuracy of 3D scanned data versus traditional manual tape measurements found no significant difference between the methods (Chun \& Oh, 2004).

Three-dimensional body scanning is an affordable means of collecting information that can be used in anthropometric studies for custom fit patternmaking or size selection in mass customized garments (Ashdown et al., 2007). Previous studies using 3D body scanners have dealt with body shapes (Chen $e t$ al., 2010; Chen, 2011; Ashdown and Na, 2008), automatic measurements (Choi \& Ashdown, 2011; Lee \& Ashdown, 2005; Lu et al., 2008), volume and shape change measurements (Staker et al., 2009), surface area measurements (Lee et al., 2006), body modeling for virtual images (Dekker et al., 1999), garment fit (Ashdown et al., 2007; Lee et al., 2006; Nam et al., 2005; Song \& Ashdown, 2010), flattening the body surface for garment patternmaking (Jeong et al., 2006; Yunchu \& Weiyuan, 2007), and observing body surface changes when in motion (Bethke, 2005; Choi, 2011; Choi \& Ashdown, 2011; Jung, 2005; Kim, 2008; Lee \& Ashdown, 2005; Lu et al., 2010; Oh \& Chun, 2008; Wang et al., 2011).

In South Korea, the common method for studying changes in the body surface during dynamic motion is to put a subject's body surface onto a grid pattern. Jung (2005), who studied cycling pants patterns, considered the curvature information of body surfaces and emphasized the necessity of developing garment patterns taking into consideration the various characteristics of muscles in order to 


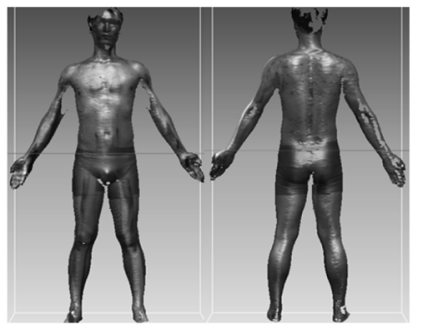

Posture I (Static standing)

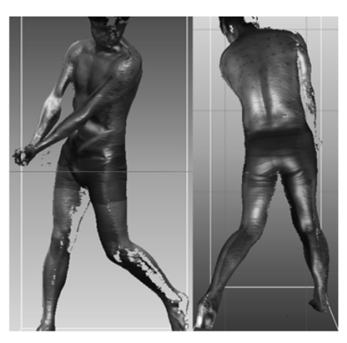

PosturelV (Impact)

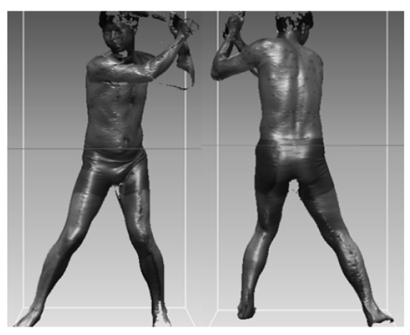

Posture II (Stride)

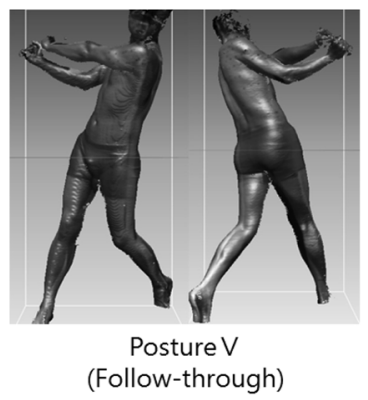

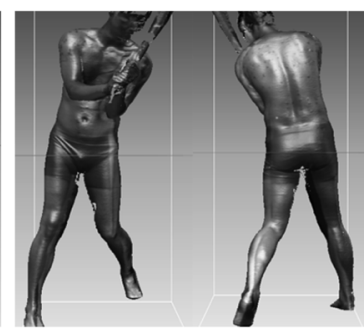

Posture III

(Swing)

Figure 1. Body Postures for the 3D Body Scanning.

improve ease of motion and comfort. Choi (2011), who studied the non-extension lines of the lower body surfaces, suggested body surface analyses focusing on the muscle contours. These studies have a common theme, muscles; however, the relationship between muscles and garment patterns is a very complex issue that has not yet been definitely resolved.

A subject's posture affects body measurements, thus each anthropometric survey standardizes the subjects' postures (Chun \& Oh, 2004). Previous studies generally used manual tape measurements (Chi \& Kennon, 2006; Wang et al., 2011) or gypsumreplicated methods (Kim et al., 1999; Kim \& Kim, 1992; Kim \& Kim, 2003) when analyzing changes in the shapes and measurements of the upper body and arms when the arms were raised upward or to the side. A 3D body scanner was used to measure dynamic postures to avoid the limitations of the traditional methods, which are related to timeconsumption and measurement errors (Chi \& Kennon, 2005; Chun, 2003; Lu et al., 2010).

Previous studies have focused primarily on arm flexion or adduction. However, the motions for daily activities, including sports and in the workplace, are predominantly articulated motions of the arms and trunk. Moreover, previous studies (Jung, 2005; Oh \& Chun, 2008; Choi \& Ashdown, 2011, Lu et al., 2010) using $3 \mathrm{D}$ body scanners focused on variations in the torso or lower body surface. Few researches had focused on the upper limbs. The purpose of this study was to analyze changes in the back body surface at the dynamic postures; it would be applied for ergonomic functional garment patternmaking.

The detailed purposes of this study were to (1) define the characteristics of back body surface changes in terms of the muscle and bone displacement at the baseball batting motions, and (2) suggest design elements for making ergonomic functional garment patterns, such as the proper fabric stretch rate.

\section{METHODS}

\section{Collecting the 3D Body Surface Scan Data}

The subject who elected for the experiment was a left-handed man capable of completing repeated baseball batting motions. He was 32-years-old man whose height $183 \mathrm{~cm}$ and with a $103.5 \mathrm{~cm}$ chest circumference and an $85 \mathrm{~cm}$ waist circumference. The subject was scanned doing one static posture and four dynamic postures were collected with a $3 \mathrm{D}$ 
body scanner (Cyberware WEB WB4) (Figure 1). At the beginning, three male subjects were scanned. One of them did not perform the baseball batting motions precisely. The other one's body scan data were not clear enough for analysis. Their body scan data were not adopted for the analysis.

Prior to scanning, researchers marked the anthropometric landmarks on the subject's body based on ISO 8559, "Garment construction and anthropometric surveys - Body dimensions" (ISO, 1989). As this study's goal was to observe back body surface variations due to muscle contraction and bony displacement, the deltoid, trapezius and scapula were determined as the representative superficial muscle and bone. An expert palpated and drew the deltoids and trapezius muscles and the scapulae on the subject's body and researchers then landmarked measuring points in order to observe detailed changes in the interior surfaces.

\section{Analyzing Changes in Back Body Surface \\ Measurements During Dynamic Postures}

The body surface dimensions were measured using the RapidForm2004 (INUS Technology Inc.) program. The surface measurements of the dynamic postures were compared with that of the static posture. This study was limited to the body surface of the back and rear upper arms. The frontal body surface data were excluded.

Surface body scanning was not completed for the shoulders as a result of the orthogonal orientation of the lasers in the scanner. To complete the missing data, a reverse engineering task called 'hole-filling' was performed; however, these data were excluded from our analyses (they were D43 and D44 of the deltoid's surface, and T2, T3, T6, T7, T9, T10, T16, T31, T32, T36, and T37 of the trapezius' surface; Figure 2).

\section{Measuring Sections of the Surface Over The Deltoids}

The range of the exterior and rear deltoids was landmarked on the subject's upper arms and shoulder girdle through palpations. The interior deltoid area was segmented into eight parts by three horizontal lines from the posterior midaxilla, the posterior axilla, and a middle point from the axilla to the insertion of the deltoid. A line that bisected the upper arm from the side was determined as a vertical base line of deltoids surface. And the space from the bisecting line to the outline of deltoids was divided into two parts. The dimensions of each part were labeled with a number: the left horizontal dimensions were D1-D9, the left vertical dimensions were D11-D24, the right horizontal dimensions were D31-39, and the right vertical dimensions were D41D54 (Figure 3).

\section{Measuring Sections of the Surface Over The Scapulae}

The surfaces over the medial border and spine of the scapula comprised the range of scapula surfaces that could be palpated. The horizontal dimensions of the

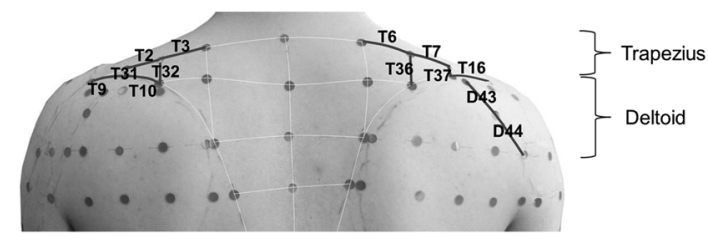

Figure 2. Dimensions Excluded in This Study.

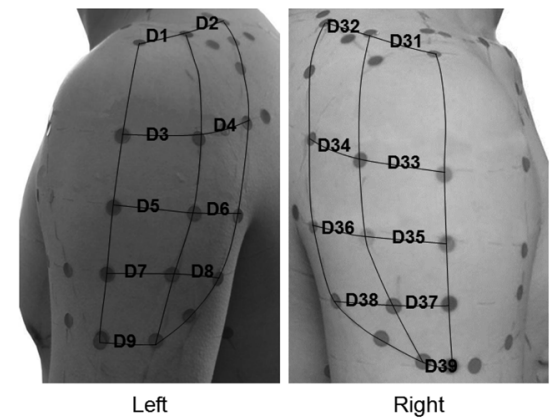

(A) Horizontal dimensions

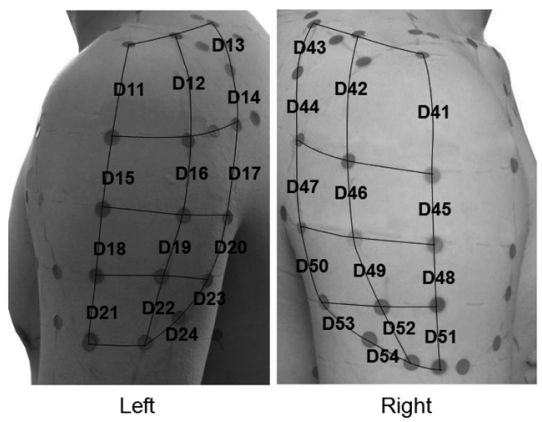

(B) Vertical dimensions

Figure 3. Measured Dimensions of the Surface Over The Deltoids. 


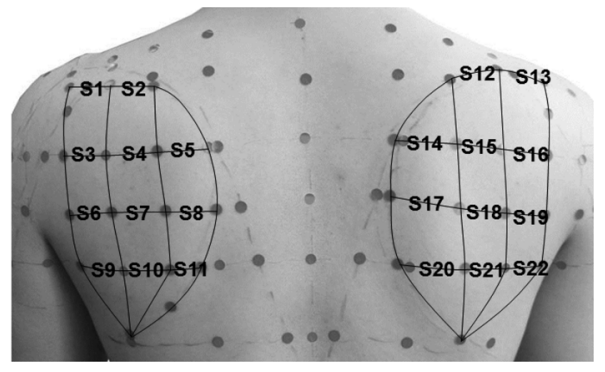

(A) Horizontal dimensions

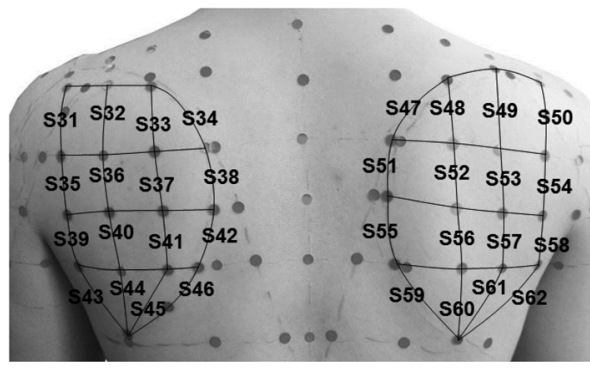

(B) Vertical dimensions

Figure 4. Measured Dimensions of the Scapular Surfaces.

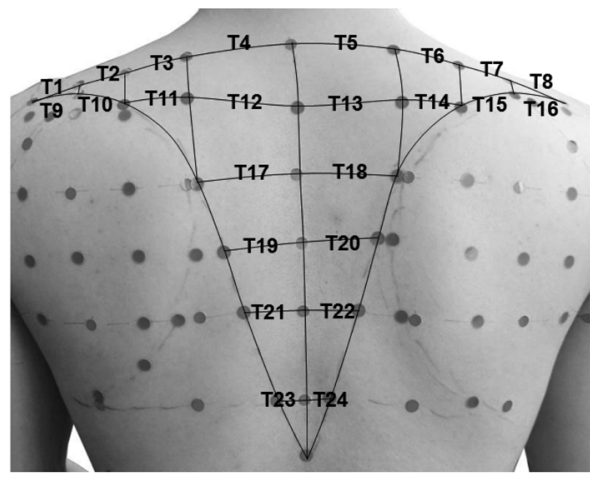

(A) Horizontal dimensions

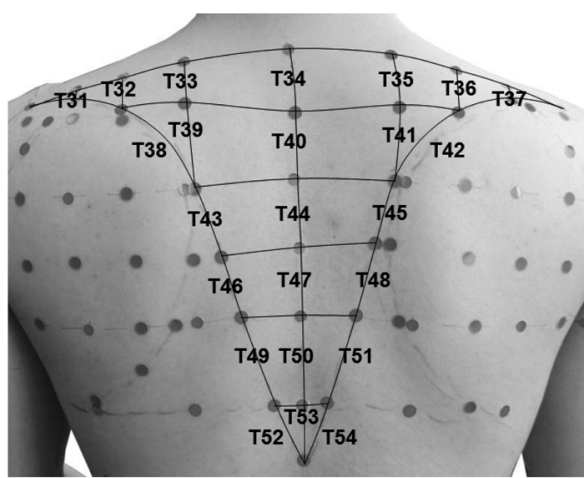

(B) Vertical dimensions

Figure 5. Measured Dimensions of the Surface Over The Trapezius.

scapula surface were determined using anthropometric dimensions: the back interscye line, the back interscye fold line, and a middle line between the back interscye fold line and a parallel line with the inferior angle of each scapula. Each horizontal line was divided into three parts. The vertical lines were determined as lines that connected one-third of each horizontal line. The dimensions of each part were labeled as follows: S1-S11, the left horizontal dimensions; S12-S22, the right horizontal dimensions; S31-S46, the left vertical dimensions; and S47-S62, the right vertical dimensions (Figure 4).

\section{Measuring Sections of the Surface Over the Trapezius}

The range of the surface for the trapezius was determined using the $12^{\text {th }}$ thoracic vertebra as the insertion and the acromia as the origin. The back interscye line, the back interscye fold line, and a crossed line with the latissimus dorsi muscle were marked on the body as the horizontal base lines. The large space (T3 T6, and T11 T14) between the lines was segmented by scapular measuring lines. The vertical dimensions were determined by the center back line and the measured points on the scapulae. The dimensions of each part were labeled either horizontally (T1-T24) or vertically (T31-T54) (Figure 5).

\section{RESULTS AND DISCUSSIONS}

\section{Measurements of the Surface Over the Deltoids}

The changing rate of the deltoid surface measurements ranged from -36.85 to $85.0 \%$ (absolute mean value of increasing rate (AMI), 16.56\%; absolute mean value of decreasing rate(AMD), 14.64\%) for the horizontal dimensions and from -47.14 to $69.42 \%$ (AMI, 19.73\%; AMD, 13.80\%) for the vertical dimensions. The amounts and directions of these variations were different for each part. The vertical measurements of the deltoids increased by over $20 \%$ compared to the horizontal dimensions (Tables 2 and 3, Figure 6). 


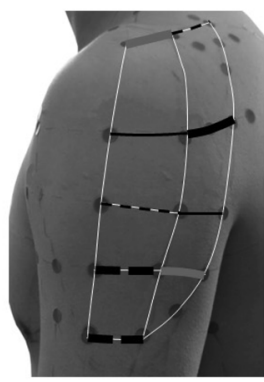

Left

(A) Horizontal measurements

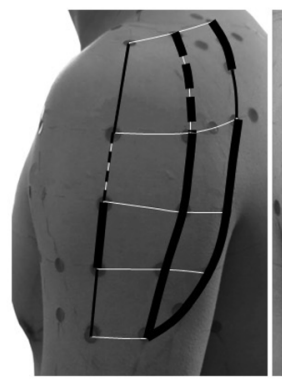

Left

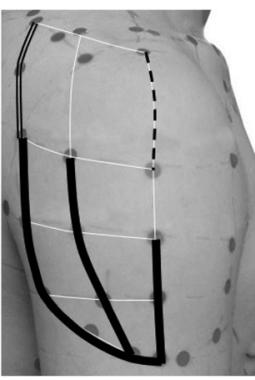

Right

(B) Vertical measurements

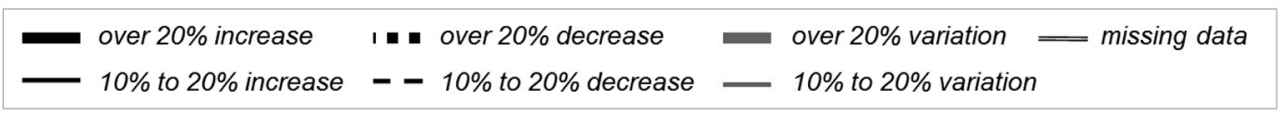

Figure 6. Body Surface Changes: Deltoids.

Table 2. Changes in Horizontal Measurements Over the Deltoid Surface for Different Dynamic Postures

\begin{tabular}{|c|c|c|c|c|c|c|c|c|c|c|}
\hline \multirow[b]{2}{*}{$\begin{array}{l}\text { Body } \\
\text { parts }\end{array}$} & \multirow{2}{*}{ Postures } & \multirow{2}{*}{$\begin{array}{c}\text { I } \\
(\text { Static }) \\
\begin{array}{c}\text { Dimensions } \\
(\mathrm{cm})\end{array}\end{array}$} & \multicolumn{2}{|c|}{$\begin{array}{c}\text { II } \\
\text { (Stride) }\end{array}$} & \multicolumn{2}{|c|}{$\begin{array}{c}\text { III } \\
\text { (Swing) }\end{array}$} & \multicolumn{2}{|c|}{$\begin{array}{c}\text { IV } \\
\text { (Impact) }\end{array}$} & \multicolumn{2}{|c|}{$\begin{array}{c}\mathrm{V} \\
\text { (Follow-through) }\end{array}$} \\
\hline & & & $\begin{array}{l}\text { Changes } \\
(\mathrm{cm})\end{array}$ & $\begin{array}{c}\text { Rate of } \\
\text { change (\%) }\end{array}$ & $\begin{array}{l}\text { Changes } \\
(\mathrm{cm})\end{array}$ & $\begin{array}{c}\text { Rate of } \\
\text { change (\%) }\end{array}$ & $\begin{array}{l}\text { Changes } \\
(\mathrm{cm})\end{array}$ & $\begin{array}{c}\text { Rate of } \\
\text { change (\%) }\end{array}$ & $\begin{array}{l}\text { Changes } \\
(\mathrm{cm})\end{array}$ & $\begin{array}{c}\text { Rate of } \\
\text { change }(\%)\end{array}$ \\
\hline \multirow{9}{*}{ Left } & D1 & 3.13 & 0.00 & 0.10 & 0.78 & 24.87 & 0.78 & 24.90 & -0.87 & -27.81 \\
\hline & D2 & 3.62 & -0.22 & -5.97 & 0.64 & 17.74 & 0.56 & 15.56 & 0.50 & 13.84 \\
\hline & D3 & 4.88 & -0.35 & -7.20 & 0.50 & 10.19 & 0.08 & 1.62 & 0.39 & 8.04 \\
\hline & D4 & 3.28 & 0.20 & 6.09 & 0.70 & 21.29 & 2.09 & 63.69 & -0.35 & -10.78 \\
\hline & D5 & 5.23 & -0.18 & -3.48 & -0.34 & -6.56 & -0.59 & -11.21 & 0.01 & 0.11 \\
\hline & D6 & 2.85 & 0.08 & 2.66 & 0.52 & 18.09 & 0.30 & 10.41 & 0.11 & 3.68 \\
\hline & D7 & 5.03 & -1.67 & -33.17 & -1.31 & -26.06 & -1.43 & -28.51 & -0.83 & -16.53 \\
\hline & D8 & 3.21 & -1.00 & -31.11 & 0.65 & 20.28 & -0.19 & -5.93 & -0.38 & -11.98 \\
\hline & D9 & 4.27 & -1.57 & -36.85 & -1.00 & -23.39 & -1.48 & -34.70 & -1.11 & -25.90 \\
\hline \multirow{9}{*}{ Right } & D31 & 3.94 & -0.50 & -12.60 & 0.04 & 0.91 & 1.07 & 27.16 & 0.58 & 14.76 \\
\hline & D32 & 3.86 & -0.04 & -1.09 & 0.27 & 7.05 & 0.46 & 12.03 & 0.61 & 15.68 \\
\hline & D33 & 5.07 & -0.40 & -7.79 & 0.32 & 6.27 & -0.15 & -3.00 & -0.68 & -13.48 \\
\hline & D34 & 3.10 & 2.66 & 85.90 & 0.56 & 18.01 & 1.48 & 47.89 & 0.66 & 21.26 \\
\hline & D35 & 4.62 & -0.45 & -9.75 & 0.33 & 7.06 & -0.07 & -1.52 & -0.68 & -14.75 \\
\hline & D36 & 4.18 & 0.42 & 10.00 & -0.08 & -2.01 & -0.52 & -12.44 & -0.53 & -12.75 \\
\hline & D37 & 3.42 & -0.48 & -14.15 & -0.42 & -12.13 & -0.13 & -3.68 & -0.72 & -20.96 \\
\hline & D38 & 3.40 & 0.08 & 2.27 & -0.15 & -4.27 & 0.06 & 1.79 & 1.36 & 39.98 \\
\hline & D39 & 1.66 & -0.03 & -1.63 & 0.25 & 14.81 & 0.01 & 0.30 & -0.53 & -31.73 \\
\hline
\end{tabular}

Note)

When the shoulder girdle was elevated (postures III and V), the horizontal measurements of the deltoid tuberosity (D7, D8, D9, D37 and D39) mostly decreased. Posture $\mathrm{V}$ had the most measurement variation. Compared to the horizontal measurements of postures II through IV, the elongation/diminution of the left arm (D1, D4 and D5) was reversed and the extent to which decreased 
Table 3. Changes in Vertical Measurements Over the Deltoid Surface for Different Dynamic Postures

\begin{tabular}{|c|c|c|c|c|c|c|c|c|c|c|}
\hline \multirow[b]{2}{*}{$\begin{array}{l}\text { Body } \\
\text { parts }\end{array}$} & \multirow[t]{2}{*}{ Postures } & \multirow{2}{*}{$\frac{\text { I }}{(\text { Static) }}$} & \multicolumn{2}{|c|}{$\begin{array}{c}\text { II } \\
\text { (Stride) }\end{array}$} & \multicolumn{2}{|c|}{$\begin{array}{c}\text { III } \\
\text { (Swing) }\end{array}$} & \multicolumn{2}{|c|}{$\begin{array}{c}\text { IV } \\
\text { (Impact) }\end{array}$} & \multicolumn{2}{|c|}{$\begin{array}{c}\mathrm{V} \\
\text { (Follow-through) }\end{array}$} \\
\hline & & & $\begin{array}{l}\text { Changes } \\
(\mathrm{cm})\end{array}$ & $\begin{array}{c}\text { Rate of } \\
\text { change (\%) }\end{array}$ & $\begin{array}{l}\text { Changes } \\
(\mathrm{cm})\end{array}$ & $\begin{array}{c}\text { Rate of } \\
\text { change (\%) }\end{array}$ & $\begin{array}{c}\text { Changes } \\
(\mathrm{cm})\end{array}$ & $\begin{array}{c}\text { Rate of } \\
\text { change (\%) }\end{array}$ & $\begin{array}{l}\text { Changes } \\
(\mathrm{cm})\end{array}$ & $\begin{array}{c}\text { Rate of } \\
\text { change }(\%)\end{array}$ \\
\hline \multirow{14}{*}{ Left } & D11 & 6.27 & -0.41 & -6.56 & 0.74 & 11.83 & 0.40 & 6.42 & 1.07 & 17.09 \\
\hline & D12 & 8.13 & -3.83 & -47.14 & 0.64 & 7.86 & -0.33 & -4.10 & -2.74 & -33.72 \\
\hline & D13 & 4.39 & 0.68 & 15.41 & 0.13 & 2.98 & 0.42 & 9.44 & 0.99 & 22.55 \\
\hline & D14 & 3.71 & 0.48 & 12.82 & 0.38 & 10.18 & 0.33 & 9.00 & -0.28 & -7.57 \\
\hline & D15 & 4.01 & -0.45 & -11.26 & 0.38 & 9.44 & 0.10 & 2.42 & 0.38 & 9.54 \\
\hline & D16 & 3.73 & 0.53 & 14.21 & 1.25 & 33.53 & 1.27 & 34.09 & 1.51 & 40.34 \\
\hline & D17 & 4.52 & 0.17 & 3.74 & 1.60 & 35.35 & 2.17 & 48.04 & 1.40 & 30.88 \\
\hline & D18 & 3.68 & -0.26 & -7.10 & 0.72 & 19.51 & 0.02 & 0.52 & 0.80 & 21.88 \\
\hline & D19 & 3.26 & 0.88 & 26.90 & 0.78 & 23.79 & 0.70 & 21.46 & 1.36 & 41.60 \\
\hline & D20 & 4.41 & 1.44 & 32.53 & 1.63 & 36.93 & 0.44 & 9.91 & 0.62 & 13.97 \\
\hline & D21 & 4.00 & 0.33 & 8.33 & 0.20 & 5.01 & 0.41 & 10.26 & 0.23 & 5.78 \\
\hline & D22 & 3.72 & 1.10 & 29.63 & 0.87 & 23.49 & 0.49 & 13.05 & 1.44 & 38.81 \\
\hline & D23 & 2.45 & 0.89 & 36.33 & 0.40 & 16.33 & 1.03 & 42.12 & 1.21 & 49.47 \\
\hline & D24 & 2.16 & 0.01 & 0.46 & 0.27 & 12.34 & 0.14 & 6.33 & 0.83 & 38.35 \\
\hline \multirow{12}{*}{ Right } & D41 & 7.16 & 0.75 & 10.53 & -1.32 & -18.45 & -0.76 & -10.54 & -0.97 & -13.53 \\
\hline & D42 & 6.49 & -0.45 & -6.94 & 0.13 & 2.06 & -0.54 & -8.24 & 0.40 & 6.14 \\
\hline & D45 & 3.70 & 0.35 & 9.36 & 0.18 & 4.73 & 0.18 & 4.92 & 0.59 & 16.07 \\
\hline & D46 & 3.57 & 1.08 & 30.22 & 0.84 & 23.52 & 0.87 & 24.42 & 1.16 & 32.49 \\
\hline & D47 & 4.01 & 1.94 & 48.45 & 0.90 & 22.34 & 1.50 & 37.38 & 0.46 & 11.35 \\
\hline & D48 & 2.86 & 0.10 & 3.32 & 0.28 & 9.69 & 0.64 & 22.53 & 0.12 & 4.09 \\
\hline & D49 & 3.46 & 0.70 & 20.33 & 1.28 & 37.08 & 0.85 & 24.60 & 0.37 & 10.63 \\
\hline & D50 & 4.22 & 1.02 & 24.05 & 0.92 & 21.77 & 0.83 & 19.59 & 1.02 & 24.21 \\
\hline & D51 & 3.22 & -0.14 & -4.29 & 0.66 & 20.58 & 0.55 & 17.13 & 0.52 & 16.26 \\
\hline & D52 & 2.91 & 0.32 & 11.02 & 1.39 & 47.63 & 1.04 & 35.66 & 0.50 & 17.12 \\
\hline & D53 & 3.32 & 0.35 & 10.67 & 0.28 & 8.41 & 0.02 & 0.75 & 0.70 & 21.21 \\
\hline & D54 & 2.53 & 0.09 & 3.72 & 0.46 & 18.24 & 0.50 & 19.66 & 1.76 & 69.42 \\
\hline Note) & & over $50 \%$ & riation & & $20 \%$ to & o variation & & & о $20 \%$ & ation \\
\hline
\end{tabular}

(D37 and D39) or to which increased (D38) of the right arm was changed conspicuously in posture V. The motional direction shifted to the opposite side in posture $\mathrm{V}$ (follow-through), whereupon the joint movements had a decisive effect on the variation in the deltoid surface measurements. The vertical lengths of the left side in posture $\mathrm{V}$ increased except for D12 (-33.72\%) and D14 (-7.57\%) around the crease where the left arm folded. Posture V was a pose in which the left arm was hyperadducted, whereas D12 and D14 were supposedly diminished.

The vertical measurements of the rear deltoid (D16, D17, D19, D50, and D53) were elongated by over $20 \%$ while the adjacent horizontal lengths (D6 and D38) significantly increased. Although the horizontal lengths D4 and D34 were similar dimensions in each arm, D4 (63.69\%) increased in posture IV to the max and D34 (85.90\%) increased in posture II to the max. The connected D17 (48.04\%) and D47 (48.45\%) were elongated by more than 
$40 \%$. The results of these analyses show that the body surface measurements between the posterior midaxilla and axilla on the rear deltoids differed considerably in different dynamic postures. Thus, dimensions around these areas should be measured to design comfortable sleeve patterns.

D34 increased at all dynamic swing postures (II, III, IV, and V). Especially in posture II (stride), D34 increased $85.9 \%$. This means that the body surface around D34 was significantly elongated by the baseball batting motions.

The horizontal measurements of the rear deltoid section (D34, D36, and D38) increased in posture II. The right upper arm was hyperadducted (AMI, $33.1 \%)$. But the horizontal measurements of the middle deltoid (D33, D35, and D37) decreased (AMD, 10.56\%). These results imply that stretch fabrics with different stretch rates at the area covering rear and middle deltoids are appropriate for the sleeve patterns of baseball shirts.

Overall, the increasing rate of deltoid surfaces was bigger than the bisecting line of upper arms. It implies that it is necessary to design sleeve patterns by determining proper extensibility of stretch fabrics or proper amounts of wearing ease. The amount of ease should be determined by considering the rates of horizontal and vertical body surface length changes.

\section{Measurements of the Surface Over the Scapulae}

Changes in the scapular surface measurements ranged from -54.88 to $129.11 \%$ (AMI, 33.02\%; AMD,

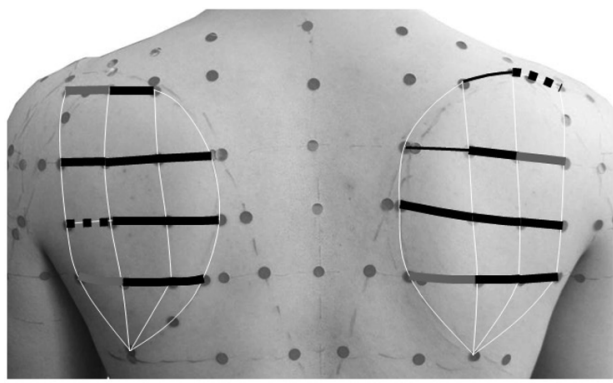

(A) Horizontal measurements
15.44\%) in the horizontal direction and from -30.36 to $74.04 \%$ (AMI, $19.10 \%$; AMD, 9.91\%) in the vertical direction (Tables 4 and 5, Figure 7). It implies that it is necessary to accommodate the rate of increase of body surfaces in the horizontal and vertical dimensions (19-33\%) in order to provide comfortable movements around scapulae.

On the surface of the scapulae, S4, S7, S8, S11, and S15 were elongated by over $10 \%$ for postures II through V. These dimensions were located on the surface between the posterior midaxilla and posterior axilla. Furthermore, changes in these surfaces had cater-cornered directivity from the acromion to the scapular medial border. Therefore, these surfaces should be considered anthropometric dimensions in the design of garments with enhanced comfort for arm motion. It could provide comfortable movements around scapulae at the upper limbs swing motions considering directivity of body surface changes.

Although the vertical measurements did not change as much as the horizontal measurements, the adjacent dimensions for the left superior part of the medial border of the scapula (S33 and S34, mean: $44.04 \%$ ) and the right scapular medial border near the inferior angle (S55, mean: 39.81\%) increased by over $20 \%$ for all of the dynamic postures. The scapular surface measurements seemed to be influenced by the displacement of the medial border and the inferior angle of the scapula. The horizontal measurements primarily decreased when the shoulder girdle was elevated and the forearm was bent (posture II).

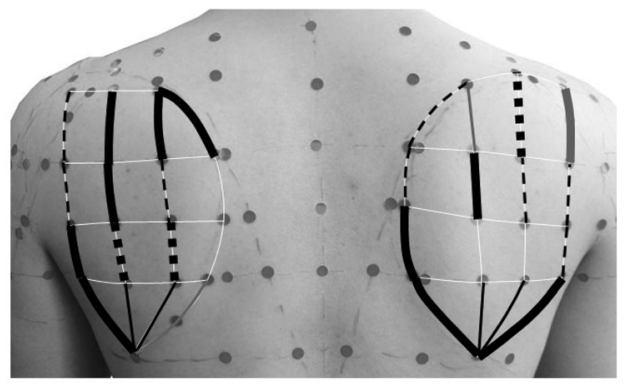

(B) Vertical measurements

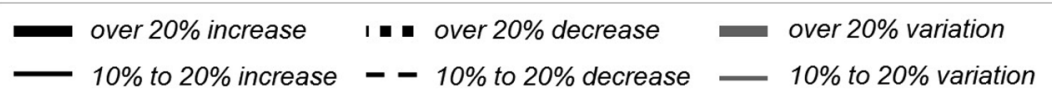

Figure 7. Body Surface Changes: Scapulae. 
Table 4. Changes in Horizontal Measurements Over the Scapular Surfaces for Different Dynamic Postures

\begin{tabular}{|c|c|c|c|c|c|c|c|c|c|c|}
\hline \multirow[b]{2}{*}{$\begin{array}{l}\text { Body } \\
\text { parts }\end{array}$} & \multirow{2}{*}{ Postures } & \multirow{2}{*}{$\frac{\text { I }}{(\text { Static })}$} & \multicolumn{2}{|c|}{$\begin{array}{c}\text { II } \\
\text { (Stride) }\end{array}$} & \multicolumn{2}{|c|}{$\begin{array}{c}\text { III } \\
\text { (Swing) }\end{array}$} & \multicolumn{2}{|c|}{$\begin{array}{c}\text { IV } \\
\text { (Impact) }\end{array}$} & \multicolumn{2}{|c|}{$\begin{array}{c}\mathrm{V} \\
\text { (Follow-through) }\end{array}$} \\
\hline & & & $\begin{array}{l}\text { Changes } \\
(\mathrm{cm})\end{array}$ & $\begin{array}{c}\text { Rate of } \\
\text { change (\%) }\end{array}$ & $\begin{array}{c}\text { Changes } \\
(\mathrm{cm})\end{array}$ & $\begin{array}{c}\text { Rate of } \\
\text { change }(\%)\end{array}$ & $\begin{array}{l}\text { Changes } \\
(\mathrm{cm})\end{array}$ & $\begin{array}{c}\text { Rate of } \\
\text { change (\%) }\end{array}$ & $\begin{array}{l}\text { Changes } \\
(\mathrm{cm})\end{array}$ & $\begin{array}{c}\text { Rate of } \\
\text { change (\%) }\end{array}$ \\
\hline \multirow{11}{*}{ Left } & S1 & 4.71 & -1.45 & -30.83 & 0.75 & 15.83 & 0.72 & 15.21 & -0.36 & -7.68 \\
\hline & S2 & 2.33 & 0.32 & 13.80 & 0.00 & -0.21 & 0.57 & 24.51 & 1.53 & 65.51 \\
\hline & S3 & 3.72 & -0.17 & -4.63 & -0.09 & -2.37 & 0.89 & 23.96 & 0.59 & 15.77 \\
\hline & S4 & 2.18 & 1.22 & 56.15 & 1.97 & 90.32 & 0.97 & 44.45 & 2.46 & 112.94 \\
\hline & S5 & 3.50 & -0.23 & -6.57 & 0.63 & 18.07 & 1.26 & 35.97 & 1.76 & 50.21 \\
\hline & S6 & 5.50 & -1.96 & -35.55 & -1.53 & -27.85 & -0.22 & -3.91 & -0.07 & -1.22 \\
\hline & S7 & 3.01 & 0.45 & 14.86 & 0.77 & 25.69 & 0.63 & 20.94 & 2.05 & 68.16 \\
\hline & S8 & 2.92 & 0.85 & 29.00 & 0.84 & 28.66 & 0.85 & 28.97 & 1.31 & 44.81 \\
\hline & S9 & 4.53 & -2.49 & -54.88 & -1.08 & -23.92 & -1.35 & -29.77 & 1.16 & 25.57 \\
\hline & $\mathrm{S} 10$ & 3.43 & 0.12 & 3.50 & 0.47 & 13.83 & 0.00 & -0.15 & 0.35 & 39.39 \\
\hline & S11 & 1.82 & 0.31 & 16.95 & 0.73 & 39.77 & 0.92 & 50.19 & 0.76 & 41.69 \\
\hline \multirow{11}{*}{ Right } & $\mathrm{S} 12$ & 4.32 & -0.38 & -8.73 & -0.23 & -5.40 & 0.56 & 12.97 & -0.33 & -7.53 \\
\hline & $\mathrm{S} 13$ & 3.66 & -1.02 & -27.92 & -0.40 & -10.98 & -1.24 & -33.77 & -1.14 & -31.04 \\
\hline & S14 & 4.82 & 0.30 & 6.13 & 0.33 & 6.75 & -0.08 & -1.70 & 0.81 & 16.80 \\
\hline & S15 & 2.56 & 3.30 & 129.11 & 0.28 & 10.76 & 1.19 & 46.64 & 1.49 & 58.26 \\
\hline & S16 & 3.59 & 1.13 & 31.33 & -0.07 & -2.01 & 0.10 & 2.90 & -0.85 & -23.64 \\
\hline & S17 & 5.22 & 0.64 & 12.25 & 0.52 & 9.91 & 0.73 & 13.92 & 1.23 & 23.63 \\
\hline & $\mathrm{S} 18$ & 3.82 & 1.09 & 28.53 & 0.22 & 5.63 & -0.12 & -3.17 & -0.10 & -2.70 \\
\hline & S19 & 2.94 & 1.73 & 58.88 & 0.17 & 5.72 & 0.44 & 15.08 & 0.00 & 0.14 \\
\hline & S20 & 3.58 & 1.40 & 39.04 & 2.37 & 66.21 & 2.30 & 64.12 & -2.20 & -61.52 \\
\hline & S21 & 3.18 & 1.97 & 61.73 & -0.35 & -10.93 & 0.12 & 3.90 & -0.02 & -0.72 \\
\hline & $\mathrm{S} 22$ & 2.80 & 1.35 & 48.22 & -0.05 & -1.85 & 0.80 & 28.57 & 0.93 & 33.13 \\
\hline Note) & & : over $50 \%$ & variation & & $20 \%$ to 5 & $0 \%$ variation & & $: 11$ & to $20 \%$ V & iation \\
\hline
\end{tabular}

Conversely, they primarily increased when the shoulder girdle was depressed and the forearm was straightened (posture V) because of the prominent bony protrusion of the scapular inferior angle.

The mean horizontal measurement change around the posterior midaxilla and posterior axilla (S3, S6, S16, S19) was approximately $10 \%$. What appeared to be perturbations were changes in these surfaces offset by different postures. Thus, these segments were affected by arm movement.

\section{Trapezius surface measurements}

The surface measurements of the trapezius changed from -29.46 to $123.85 \%$ (AMI, 38.58\%; AMD, $12.42 \%$ ) for the horizontal dimensions and from
-33.03 to $78.79 \%$ (AMI, 23.64\%; AMD, 18.02\%) for the vertical dimensions (Tables 6 and 7, Figure 8). Compared to the other postures, the changes in the horizontal measurements were small for posture II, as it seemed that the trunk's rotation had less of an effect for this posture.

Most of the horizontal measurements were lengthened by more than $10 \%$, especially around the lower back (T19, T20, T21, T23 and T24) where the elongation was approximately $50 \%$. The vertical measurements at the center back and adjacent horizontal measurements elongated by more than $10 \%$ due to the flexion and rotation of the trunk. Kim et al. (1999), after observing body surface changes with the arms raised upward, mentioned 
Table 5. Changes in Vertical Measurements Over the Scapular Surfaces for Different Dynamic Postures

\begin{tabular}{|c|c|c|c|c|c|c|c|c|c|c|}
\hline \multirow[b]{2}{*}{$\begin{array}{l}\text { Body } \\
\text { parts }\end{array}$} & \multirow[t]{2}{*}{ Postures } & \multirow{2}{*}{$\begin{array}{c}\text { I } \\
(\text { Static }) \\
\begin{array}{c}\text { Dimensions } \\
(\mathrm{cm})\end{array}\end{array}$} & \multicolumn{2}{|c|}{$\begin{array}{c}\text { II } \\
\text { (Stride) }\end{array}$} & \multicolumn{2}{|c|}{$\begin{array}{c}\text { III } \\
\text { (Swing) }\end{array}$} & \multicolumn{2}{|c|}{$\begin{array}{c}\text { IV } \\
\text { (Impact) }\end{array}$} & \multicolumn{2}{|c|}{$\begin{array}{c}\mathrm{V} \\
\text { (Follow-through) }\end{array}$} \\
\hline & & & $\begin{array}{l}\text { Changes } \\
(\mathrm{cm})\end{array}$ & $\begin{array}{c}\text { Rate of } \\
\text { change }(\%)\end{array}$ & $\begin{array}{l}\text { Changes } \\
(\mathrm{cm})\end{array}$ & $\begin{array}{c}\text { Rate of } \\
\text { change }(\%)\end{array}$ & $\begin{array}{l}\text { Changes } \\
\text { (cm) }\end{array}$ & $\begin{array}{c}\text { Rate of } \\
\text { change }(\%)\end{array}$ & $\begin{array}{l}\text { Changes } \\
(\mathrm{cm})\end{array}$ & $\begin{array}{c}\text { Rate of } \\
\text { change }(\%)\end{array}$ \\
\hline \multirow{16}{*}{ Left } & S31 & 5.91 & 0.14 & 2.30 & -0.86 & -14.49 & -0.40 & -6.85 & -0.40 & -6.75 \\
\hline & S32 & 5.50 & 0.74 & 13.35 & 1.04 & 18.86 & 1.86 & 33.78 & -0.32 & -5.80 \\
\hline & S33 & 3.50 & 1.90 & 54.33 & 0.94 & 26.84 & 0.94 & 26.89 & 1.44 & 41.21 \\
\hline & S34 & 4.25 & 1.58 & 37.14 & 1.85 & 43.61 & 2.05 & 48.22 & 3.15 & 74.04 \\
\hline & S35 & 4.63 & -0.20 & -4.30 & 0.01 & 0.19 & -0.79 & -16.97 & -0.57 & -12.41 \\
\hline & S36 & 3.62 & 0.60 & 16.67 & 0.09 & 2.54 & 0.86 & 23.84 & 0.70 & 19.26 \\
\hline & S37 & 4.74 & -0.57 & -12.09 & -0.13 & -2.76 & -0.44 & -9.35 & -0.26 & -5.47 \\
\hline & S38 & 4.47 & 0.00 & -0.09 & 0.33 & 7.36 & 0.13 & 3.00 & 0.15 & 3.29 \\
\hline & S39 & 4.29 & 0.29 & 6.83 & 1.57 & 36.61 & 3.14 & 73.30 & -0.25 & -5.81 \\
\hline & $\mathrm{S} 40$ & 5.96 & -1.15 & -19.26 & -0.57 & -9.55 & -1.76 & -29.55 & -1.41 & -23.59 \\
\hline & S41 & 5.35 & -0.90 & -16.84 & -0.47 & -8.77 & -0.72 & -13.55 & -1.15 & -21.42 \\
\hline & $\mathrm{S} 42$ & 4.70 & -0.07 & -1.49 & 0.27 & 5.79 & -0.20 & -4.23 & -0.44 & -9.28 \\
\hline & S43 & 5.74 & 0.73 & 12.79 & 1.00 & 17.46 & -0.11 & -1.83 & 3.40 & 59.21 \\
\hline & S44 & 5.36 & 0.28 & 5.19 & 0.67 & 12.47 & -0.09 & -1.72 & 0.30 & 5.60 \\
\hline & S45 & 6.20 & 0.37 & 5.96 & 0.95 & 15.25 & 0.56 & 9.02 & -0.42 & -6.79 \\
\hline & S46 & 7.64 & 0.13 & 1.65 & 0.80 & 10.42 & 1.11 & 14.46 & -0.82 & -10.77 \\
\hline \multirow{16}{*}{ Right } & S47 & 6.79 & 0.28 & 4.05 & -0.71 & -10.40 & -0.34 & -5.01 & 0.28 & 4.15 \\
\hline & S48 & 4.88 & -0.75 & -15.30 & -0.44 & -8.95 & -0.10 & -1.97 & 0.60 & 12.27 \\
\hline & S49 & 7.06 & -2.13 & -30.17 & -2.14 & -30.36 & -2.06 & -29.17 & -0.63 & -8.88 \\
\hline & $\mathrm{S} 50$ & 6.54 & 0.67 & 10.30 & -0.30 & -4.51 & -1.58 & -24.09 & -0.70 & -10.75 \\
\hline & S51 & 4.95 & -0.06 & -1.15 & -0.31 & -6.23 & -0.89 & -17.94 & -0.92 & -18.58 \\
\hline & S52 & 4.90 & 0.15 & 3.16 & 0.03 & 0.57 & 0.19 & 3.82 & 2.36 & 48.18 \\
\hline & S53 & 5.11 & -0.52 & -10.22 & -0.18 & -3.44 & 0.02 & 0.49 & -0.15 & -2.98 \\
\hline & S54 & 4.72 & -0.52 & -11.13 & -0.36 & -7.70 & -0.01 & -0.23 & 0.19 & 4.05 \\
\hline & S55 & 3.72 & 1.08 & 28.93 & 1.91 & 51.28 & 1.71 & 46.09 & 1.23 & 32.94 \\
\hline & S56 & 4.70 & -0.25 & -5.40 & 0.35 & 7.38 & -0.04 & -0.89 & 0.01 & 0.30 \\
\hline & S57 & 4.41 & -0.41 & -9.35 & 0.20 & 4.61 & -0.08 & -1.86 & -0.21 & -4.74 \\
\hline & $\mathrm{S} 58$ & 4.46 & -0.69 & -15.50 & -0.57 & -12.85 & -0.43 & -9.55 & 0.08 & 1.77 \\
\hline & S59 & 7.30 & 0.07 & 0.95 & 0.89 & 12.20 & 0.71 & 9.73 & 3.23 & 44.23 \\
\hline & S60 & 5.72 & -0.01 & -0.24 & 1.02 & 17.79 & 0.80 & 13.92 & -0.17 & -2.94 \\
\hline & S61 & 6.15 & 0.66 & 10.74 & 0.95 & 15.39 & 0.64 & 10.34 & -0.01 & -0.16 \\
\hline & S62 & 7.25 & 3.21 & 44.28 & 1.11 & 15.27 & 1.76 & 24.26 & 0.54 & 7.45 \\
\hline Note) & & : over $50 \%$ & variation & & $: 20 \%$ to 5 & $0 \%$ variation & & & $: 10 \%$ to & $\%$ variation \\
\hline
\end{tabular}

that the arm flexion motion had less of an effect on changes in measurements around the center back. The body surface around the center back changed noticeably when the upper body rotated; therefore, it is necessary to measure the length of the back interscye fold line to the crossed line with the latissimus dorsi muscle at the center back in order to design comfortable garments for wearers needing a 


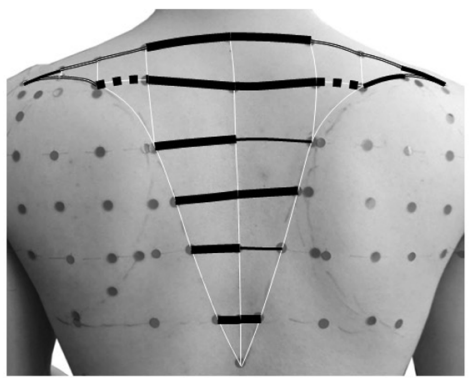

(A) Horizontal measurements

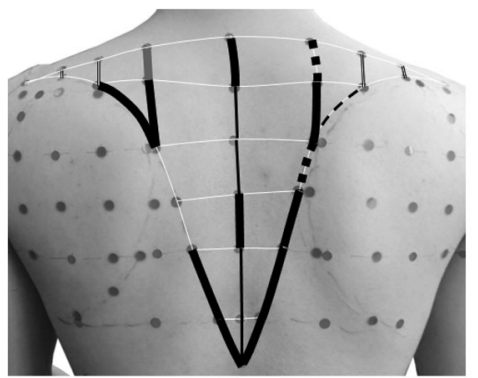

(B) Vertical measurements

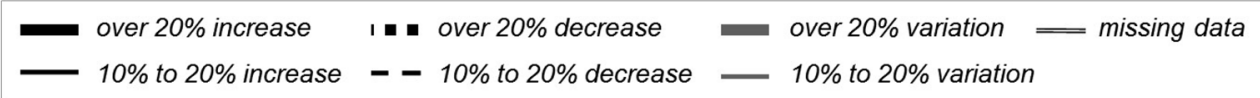

Figure 8. Body surface changes: Trapezius.

Table 6. Changes in Horizontal Measurement Over the Trapezius Surface for Different Dynamic Postures

\begin{tabular}{|c|c|c|c|c|c|c|c|c|c|c|}
\hline \multirow[b]{2}{*}{$\begin{array}{l}\text { Body } \\
\text { parts }\end{array}$} & \multirow[t]{2}{*}{ Postures } & \multirow{2}{*}{$\frac{\mathrm{I}}{(\text { Static })}$} & \multicolumn{2}{|c|}{$\begin{array}{c}\text { II } \\
\text { (Stride) }\end{array}$} & \multicolumn{2}{|c|}{$\begin{array}{c}\text { III } \\
\text { (Swing) }\end{array}$} & \multicolumn{2}{|c|}{$\begin{array}{c}\text { IV } \\
\text { (Impact) }\end{array}$} & \multicolumn{2}{|c|}{$\begin{array}{c}\mathrm{V} \\
\text { (Follow through) }\end{array}$} \\
\hline & & & $\begin{array}{l}\text { Changes } \\
(\mathrm{cm})\end{array}$ & $\begin{array}{c}\text { Rate of } \\
\text { change (\%) }\end{array}$ & $\begin{array}{l}\text { Changes } \\
(\mathrm{cm})\end{array}$ & $\begin{array}{c}\text { Rate of } \\
\text { change (\%) }\end{array}$ & $\begin{array}{l}\text { Changes } \\
(\mathrm{cm})\end{array}$ & $\begin{array}{c}\text { Rate of } \\
\text { change (\%) }\end{array}$ & $\begin{array}{l}\text { Changes } \\
(\mathrm{cm})\end{array}$ & $\begin{array}{c}\text { Rate of } \\
\text { change (\%) }\end{array}$ \\
\hline \multirow{8}{*}{ Left } & $\mathrm{T} 1$ & 3.62 & -0.22 & -5.97 & 0.64 & 17.74 & 0.56 & 15.56 & 0.50 & 13.84 \\
\hline & $\mathrm{T} 4$ & 5.32 & 0.68 & 12.82 & 0.54 & 10.15 & 0.34 & 6.47 & 2.08 & 39.09 \\
\hline & T11 & 5.27 & -1.14 & -21.65 & 0.04 & 0.78 & -0.20 & -3.81 & -0.83 & -15.68 \\
\hline & T12 & 5.34 & 2.28 & 42.74 & 2.87 & 53.81 & 2.44 & 45.79 & 2.72 & 50.93 \\
\hline & $\mathrm{T} 17$ & 5.75 & 0.51 & 8.90 & 1.62 & 28.17 & 1.85 & 32.19 & 1.69 & 29.41 \\
\hline & T19 & 3.71 & 1.23 & 33.06 & 2.25 & 60.81 & 1.84 & 49.72 & 2.24 & 60.46 \\
\hline & $\mathrm{T} 21$ & 2.60 & 1.11 & 42.65 & 1.45 & 55.77 & 2.03 & 78.15 & 2.73 & 105.04 \\
\hline & $\mathrm{T} 23$ & 1.02 & 0.63 & 62.22 & 0.70 & 68.30 & 0.70 & 68.60 & 1.26 & 123.85 \\
\hline \multirow{9}{*}{ Right } & $\mathrm{T} 5$ & 5.12 & 0.31 & 6.05 & 1.37 & 26.72 & 1.37 & 26.64 & 1.45 & 28.34 \\
\hline & $\mathrm{T} 8$ & 3.86 & -0.04 & -1.09 & 0.27 & 7.05 & 0.46 & 12.03 & 0.61 & 15.68 \\
\hline & T13 & 5.88 & 1.40 & 23.78 & 1.34 & 22.80 & 1.40 & 23.85 & 1.10 & 18.68 \\
\hline & T14 & 5.32 & -0.52 & -9.81 & -1.49 & -28.00 & -1.57 & -29.46 & -1.19 & -22.28 \\
\hline & $\mathrm{T} 15$ & 4.25 & -0.19 & -4.52 & -0.17 & -3.93 & 0.63 & 14.82 & 0.35 & 8.12 \\
\hline & T18 & 6.17 & 0.47 & 7.57 & 1.11 & 18.02 & 0.98 & 15.88 & 1.16 & 18.84 \\
\hline & $\mathrm{T} 20$ & 3.07 & 2.67 & 87.21 & 2.92 & 95.40 & 2.77 & 90.28 & 2.31 & 75.27 \\
\hline & $\mathrm{T} 22$ & 3.38 & 0.24 & 7.16 & 0.64 & 18.86 & 0.37 & 10.94 & -0.09 & -2.81 \\
\hline & $\mathrm{T} 24$ & 1.02 & 0.60 & 58.49 & 0.64 & 62.61 & 0.66 & 64.77 & 0.79 & 77.33 \\
\hline Note) & & : over $50 \%$ & ariation & & $: 20 \%$ to & $\%$ variation & & & $20 \%$ & tion \\
\hline
\end{tabular}

wide range of upper body movement. The absolute mean value of vertical length changes ratio was about $24 \%$. This result implies that there is a need to extend the back length of a shirt pattern to prevent from rolling up at arms on torso.

\section{CONCLUSIONS}

Determining the predominant changes in body measurements is a critical step in explaining the effect of joint movements on clothing. The aim of this study was to ascertain how the superficial 
Table 7. Changes in Vertical Measurements Over the Trapezius Surface for Different Dynamic Postures

\begin{tabular}{|c|c|c|c|c|c|c|c|c|c|c|}
\hline \multirow[b]{2}{*}{$\begin{array}{l}\text { Body } \\
\text { parts }\end{array}$} & \multirow[t]{2}{*}{ Postures } & \multirow{2}{*}{$\frac{\mathrm{I}}{(\text { Static })}$} & \multicolumn{2}{|c|}{$\begin{array}{c}\text { II } \\
\text { (Stride) }\end{array}$} & \multicolumn{2}{|c|}{$\begin{array}{c}\text { III } \\
\text { (Swing) }\end{array}$} & \multicolumn{2}{|c|}{$\begin{array}{c}\text { IV } \\
\text { (Impact) }\end{array}$} & \multicolumn{2}{|c|}{$\begin{array}{c}\mathrm{V} \\
\text { (Follow through) }\end{array}$} \\
\hline & & & $\begin{array}{l}\text { Changes } \\
\text { (cm) }\end{array}$ & $\begin{array}{c}\text { Rate of } \\
\text { change (\%) }\end{array}$ & $\begin{array}{l}\text { Changes } \\
(\mathrm{cm})\end{array}$ & $\begin{array}{c}\text { Rate of } \\
\text { change }(\%)\end{array}$ & $\begin{array}{l}\text { Changes } \\
\text { (cm) }\end{array}$ & $\begin{array}{c}\text { Rate of } \\
\text { change (\%) }\end{array}$ & $\begin{array}{c}\text { Changes } \\
(\mathrm{cm})\end{array}$ & $\begin{array}{c}\text { Rate of } \\
\text { change }(\%)\end{array}$ \\
\hline \multirow{7}{*}{ Left } & T33 & 3.75 & -0.67 & -17.78 & -1.15 & -30.73 & 1.26 & 33.58 & -0.70 & -18.68 \\
\hline & T38 & 6.73 & -0.60 & -8.88 & 1.91 & 28.31 & 1.53 & 22.77 & 0.83 & 12.28 \\
\hline & T39 & 4.38 & 2.89 & 65.88 & 0.64 & 14.63 & 0.61 & 13.99 & 1.29 & 29.35 \\
\hline & T43 & 4.88 & -0.04 & -0.86 & 0.36 & 7.28 & 0.39 & 8.06 & 0.26 & 5.39 \\
\hline & T46 & 4.31 & 0.18 & 4.10 & 0.41 & 9.43 & 0.06 & 1.30 & 0.36 & 8.25 \\
\hline & T49 & 6.31 & 1.44 & 22.80 & 0.94 & 14.87 & 1.29 & 20.52 & 1.49 & 23.66 \\
\hline & T52 & 3.31 & 0.87 & 26.24 & 1.05 & 31.82 & 1.43 & 43.15 & 2.38 & 71.98 \\
\hline \multirow{6}{*}{ Center } & T34 & 3.16 & 2.49 & 78.79 & 1.47 & 46.47 & 2.34 & 73.92 & 1.45 & 45.74 \\
\hline & $\mathrm{T} 40$ & 4.35 & 0.68 & 15.55 & 0.27 & 6.30 & 0.35 & 8.15 & -0.21 & -4.81 \\
\hline & T44 & 3.62 & 0.36 & 9.80 & 0.52 & 14.27 & 0.45 & 12.39 & 0.50 & 13.91 \\
\hline & $\mathrm{T} 47$ & 4.17 & 0.31 & 7.50 & 1.11 & 26.56 & 1.04 & 24.89 & 0.73 & 17.41 \\
\hline & T50 & 5.91 & 0.79 & 13.38 & 0.49 & 8.32 & 0.23 & 3.86 & 0.26 & 4.41 \\
\hline & T53 & 3.99 & 0.61 & 15.40 & 0.76 & 18.94 & 0.59 & 14.70 & 0.35 & 8.81 \\
\hline \multirow{7}{*}{ Right } & T35 & 4.63 & -1.25 & -26.89 & -1.46 & -31.53 & -1.08 & -23.29 & 0.06 & 1.38 \\
\hline & T41 & 4.18 & 1.18 & 28.19 & 0.56 & 13.36 & 1.13 & 26.97 & 1.27 & 30.36 \\
\hline & T42 & 7.44 & -0.31 & -4.18 & -0.90 & -12.13 & -1.19 & -15.93 & -1.15 & -15.38 \\
\hline & T45 & 5.52 & -1.82 & -33.03 & -0.76 & -13.82 & -1.18 & -21.45 & -1.49 & -27.01 \\
\hline & T48 & 3.88 & 1.21 & 31.17 & 1.62 & 41.81 & 1.18 & 30.35 & 1.02 & 26.22 \\
\hline & T51 & 5.74 & 1.24 & 21.63 & 1.48 & 25.81 & 1.09 & 18.94 & 0.17 & 2.87 \\
\hline & T54 & 3.39 & 1.67 & 49.15 & 1.62 & 47.88 & 1.52 & 44.69 & 1.33 & 39.15 \\
\hline Note) & & over $50 \%$ & ariation & & $20 \%$ to & $\%$ variation & & $: 10$ & o $20 \%$ & riation \\
\hline
\end{tabular}

muscles and bony displacement affect changes in the body surface measurements of dynamic postures. We analyzed changes in the body surface measurements by observing four baseball batting postures requiring various movements of the upper limbs. The measured areas were defined by the areas of the deltoid, trapezius and scapula. To analyze changes in the body surface measurements as a function of posture, scanned data of the dynamic postures were obtained and subtracted from that collected for the static posture.

Some parts (D16, D54, S34, T21, T23, T24 and T52) progressively increased according to phases of baseball batting postures, but most of the dimensions changed differently for the different postures. A wide range of variations in body surface dimensions was observed in the follow-through posture. In the stride posture, the subject strode forward and raised his arms up to shoulder level, and the horizontal measurement around the posterior axilla on the left scapula mainly decreased; however, the right side increased to a high of $58.88 \%$. The horizontal measurements near the posterior axilla on the deltoids varied by over $10 \%$. The surfaces around the scapular medial border were mostly elongated. The movements of the arms veered to opposite sides in the follow-through posture, whereupon the majority of the vertical measurements on the deltoid surface were elongated by over $20 \%$. Furthermore, the horizontal measurements of the surface for the scapulae and the trapezius primarily increased. In the follow-through posture, the changes in the vertical measurements of the trapezius' center surface, namely the center back 
line, were less than in other postures because of the trunk's rotation.

Although the changes in the deltoid surface were not significant, many of the horizontal directions changed in the impact and follow-through postures. On the scapular surface, the horizontal measurements for the left side increased in the impact and followthrough postures; however, the right side increased in the stride posture. The vertical measurements elongated during the swing and impact postures. On the surface of the trapezius, the horizontal measurements increased particularly from the swing to the follow-through postures, while the vertical measurements changed similarly for all postures.

Overall, the posture most useful for assessing changes in the body surface on the humeri and upper body is the follow-through posture. It is a compound posture wherein the arms move to the hyper level (hyperadduction/hyperabduction) and the trunk is rotated. We assumed that it is a posture entailing the full movement that a person would experience in their normal daily activities, including both sports and at work. Therefore, a posture with movements corresponding to the follow-through posture need to be considered when designing ergonomic functional clothing for environments where motion stability and kinetic functionality are necessary. The surface from the posterior midaxilla to the posterior axilla changed most notably; therefore, the scapula and trapezius area are important regions to consider when making garments for wearers whose daily activities consist of dynamic motions with the arms and upper body.

Compared to the measurements for the static posture, the dynamic postures showed variations for different parts of the muscles and bone. These results indicate that body surface changes due to movements of the upper arms are under the influence of both the deltoid articulated with the humeri and the scapulae and trapezius. The results of this study indicate that body surface changes, namely on the deltoids, scapulae and trapezius, can be used to design patterns for ergonomic functional clothing to improve kinetic comfort and ease of movement. In future studies, we are going to examine the proper amount of wearing ease for ergonomic functional clothing based on results of this study.

To summarize, dynamic postures in the form of baseball batting motions were examined as segmented poses. Whereas previous studies assessed postures with the arms raised upward or sideways, this study analyzed motion during an activity. Future research should examine body surface changes during continuous motion.

This is an empirical case study. The results of this study should be interpreted with caution because of the number of subject. The aim of this research was analyzed segmented body surfaces with muscle and bone displacement in dynamic posture. The results proposed some considerable issue for making garment patterns with the enhanced kinetic functionality of upper arms in the form of baseball batting motions.

\section{REFERENCES}

Ashdown, S. P., Choi, M. S., \& Milke, E. (2007). Automated side-seam placement from 3D body scan data. International Journal of Clothing Science and Technology, 20(4), 199-213.

Ashdown, S. P., \& Na, H. S. (2008). Comparison of 3D body scan data to quantify upper-body postural variation in older and younger women. Clothing and Textiles Research Journal, 26(4), 292-307.

Bethke, K. (2005). The second skin approach: skin strain field analysis and mechanical counter pressure prototyping for advanced spacesuit design. Master's thesis, Massachusetts institute of technology, Massachusetts, USA.

Chen, C. M., LaBat, K., \& Bye, E. (2010). Physical characteristics related to bra fit. Ergonomics, 53(4), 514-524.

Chen, C. (2011). Analysis of upper physical characteristics based on angle measurements. Textile Research Journal, 81(3), 301-310.

Chi, L. \& Kennon, R. (2006). Body scanning of dynamic posture. International Journal of Clothing Science and Technology, 18(3), 166-178.

Choi, J. Y. (2011). Engineering design of 3D tight-fit gar- 
ment using skin surface mapping based on the skin deformation of lower body. Master's thesis, Chungnam National University, Chungnam, Korea.

Choi, S. Y., \& Ashdown, S. P. (2011). 3D body scan analysis of dimensional change in lower body measurements for active body positions. Textile Research Journal, 8(1), 81-93.

Chun, J. S. (2003). A study on use of anthropometric data and 3D body scan data at apparel industry. International journal of Costume Culture, 6(1), 19-29.

Chun, J. S., \& Oh, S. Y. (2004). 3D body scanning posture to collect anthropometric data for garment making. Journal of Asian Regional Association for Home Economics, 11, 301-307.

Çivitci, Ş. (2004). An ergonomic garment design for elderly Turkish men. Applied Ergonomics, 35, 243-251.

Daanen, H. A. M., \& M.Sc, G. J. W. (1998). Whole body scanner. Displays, 19, 111-120.

Dekker, L., Douros, I., Buxton, B. F., \& Treleaven, P. (1999, October). Building symbolic information for 3D human body modeling from range data. Paper presented at the Second International Conference on 3-D Digital Imaging and Modeling, Ottawa, Canada.

Jeong, Y., Hong, K., \& Kim, S. J. (2006). 3D pattern construction and its application to tight-fitting garments for comfortable pressure sensation. Fibers and Polymers, 7(2), 195-202.

Jung, Y. H. (2005). Pattern development of cycling pants from 3D human scan data considering the moving posture and the curvature plot for comfortable pressure sensation. Doctoral Dissertation, Chungnam National University, Chungnam, Korea.

Kim, M. K., \& Kim, H. K. (1992). A study on the upper part of the body form variation according to arm movements for male by plater gypsum experiments. Journal of the Korean Home Economics Association, 30(3), 63-77.

Kim, H. K., Suh, C. Y. \& Park, S. J. (1999). Study on the determination of ease amount according to the body surface of upper arm and scapula. Annual Report of Human Ecology Research Institute, 13, 1-8.

Kim, Y. H., \& Kim, Y. S. (2003). Considerable differ- ences of body surface area in the preparation of bicycle wear. The Research Journal of the Costume Culture, 11(3), 375-386.

Kouchi, M., \& Mochimaru, M. (2011). Errors in landmarking and the evaluation of the accuracy of traditional and 3D anthropometry. Applied Ergonomics, 42, 518-527.

Lee, J. R., \& Ashdown, S. P. (2005). Upper body surface change analysis using 3-D body scanner. Journal of Korean Society of Clothing and Textiles, 29(12), 1595-1607.

Lee, Y. A., Ashdown, S. P., \& Slocum, A. C. (2006). Measurement of surface area of 3-D body scans to assess the effectiveness of hats for sun protection. Family and Consumer Sciences Research Journal, 34(4).

Lu, J. M., \& Wang M. J. J. (2008). Automated anthropometric data collection using 3D whole body scanners. Expert Systems with Applications, 35, 407414.

Lu, J. M., Wang, M. J. J., \& Mollard, R. (2010). The effect of arm posture on the scan-derived measurements. Applied Ergonomics, 41, 236-241.

Nam, J. H., Branson, D. H., Cao, H., Jin, B. H., \& Ashdown, S. (2005). Fit analysis of liquid cooled vest prototypes using 3D body scanning Technology. Journal of Textile and Apparel, Technology and Management, 4(3), 1-13.

Oh, S. Y., \& Chun, J. S. (2008). The changes of three dimensional body measurements in golf swing postures. Journal of Asian Regional Association for Home Economics, 15, 146-157.

Song, H. K., \& Ashdown, S. P. (2010). An exploratory study of the validity of visual fit assessment from three-dimensional scans. Clothing and Textiles Research Journal, 28(4), 263-278.

Staker, M., Ryan, K., \& LaBar, K. (2009). Medicine and design investigate residual limb volume fluctuations: three case studies. Australasian Medical Journal, 1(12), 156-161.

Toney, A., Dunne, L., Tomas, B. H., \& Ashdown, S. P. (2003, October). A shoulder pad insert vibrotactile display. Paper presented at the Seventh IEEE International Symposium on Wearable Computers, 
White Plains, New York.

Wang, Y. J., Mok, P. Y., \& Kwok, Y. L. (2011). Body measurements of Chinese males in dynamic postures and application. Applied Ergonomics, 42, 900912.

Yunchu, Y., \& Weiquan, Z. (2007). Prototype garment pattern flattening based on individual 3D virtual dummy.

Received September 28, 2012

Revised January 18, 2013

Accepted February 13, 2013 